\title{
The Impact of Restaurant Atmospherics Towards Restaurant Patrons' Behavioral Intention in Southern Province of Sri Lanka
}

\author{
W.G.G.A. Chandra ${ }^{1 *}$ N.P. Wickramasekara ${ }^{2}$ \\ 1. Department of Accountancy, Galle Advanced Technological Institute, Sri Lanka Institute of Advanced \\ Technological Education, Galle, Sri Lanka. \\ 2. Department of Accountancy, Galle Advanced Technological Institute, Sri Lanka Institute of Advanced \\ Technological Education, Galle, Sri Lanka. \\ * E-mail of the corresponding author: chanduwijesekara@gmail.com
}

\begin{abstract}
This study investigated the impact of atmospherics on the behavioral intention of restaurant patrons in Galle and Matara Districts in Southern Province of Sri Lanka. Based on the review of extensive literature pertaining to the store atmospherics, researchers examined four store atmospheric variables as exterior, general interior and decorations, human variable (employees) and layout \& design. The data were collected over Mall Intercept Survey technique by randomly administering structured questionnaires to 300 respondents in Galle and Matara districts. First ANOVA test was performed to measure the fitness of the model and simple regression analysis was conducted to investigate the impact of atmospheric variables on behavioral intention. The results of the regression analysis indicated that restaurant atmospherics have an impact on behavioral intention of restaurant patrons. Moreover, it indicated that interior atmospheric variable (Cleanliness, Lighting, Foods/Beverages) was the most significant atmospheric variable which determine the behavioral intention in restaurant industry.
\end{abstract}

Keywords: Atmospheric variables, Behavioral intention, Patrons, Restaurants.

DOI: $10.7176 / \mathrm{EJBM} / 13-1-02$

Publication date: January $31^{\text {st }} 2021$

\section{Introduction}

Consumer preferences have been changing rapidly in the world and consumers are not only buying foods and beverages, they are expecting a great dining experience in a pleasant environment. Blum (1996) stated that food service industry operators' employing strategies are not so longer benefited with the changes of consumer's preferences in the world.

Around forty-seven years back, Kotler (1973) stated unique atmosphere as the most influential tools for generating repurchase behavior and consumers are making store selection decision by relying on store atmosphere rather than the merchandise they supplied. According to the author, atmospherics recognized as a crucial marketing tool for retailers and which was identified as a primary product which is affecting on purchase decision significantly. Moreover, it stated that consumers are more responding to attractive atmosphere rather than the tangible product or services they offered and creation of unique attractive retail atmosphere is becoming a great strategy to grab consumers to outlets at the immense competition. It is also reflected by Baker \& Grewal (1994) as the physical attractiveness of store make great influence on behavioral intention than quality of merchandise and prices.

The store personality which is attitude of management and culture of company is reflected over the atmospherics and it directly impact on consumers' store choice and behavioral intention. The atmosphere causes to attract more customers to outlets and assists build behavioral intention in mindset of consumers. Now restaurant managers spend millions of dollars to create more recreational and attractive physical surroundings in restaurant as a strategy. As well as restaurant operator are applying nature of the atmosphere to classify the business as friendly neighbor restaurant, elite, upper scale store, and family retail shop, fashion forward store, store destination etc.

\subsection{Problem Statement}

The academics interest in how atmospherics influence on consumer patron's behavioral intention has grown with the article wrote by the Kotler in 1973. It indicated a new avenue for Marketing Literature by highlighting as atmosphere is a significant factor than the tangibles provided by the retailers.

Thus, previous researchers examined the influence of store atmosphere at different research settings and revealed that What appeals to consumers' preferences are not only food and beverages, an enjoyable dining atmosphere 
also matters. Increasing attention is being paid not only to pricing and the merchandise itself, but also to the provision of a pleasant and possibly exciting, shopping atmosphere (Baker 1986; Baker et al. 1992; Dawson et al. 1990; Sherman et al. 1997; Sherman \& Smith 1986).

However, the research works on investigation the impact of atmospherics on behavioral intention are still limited (Turley \& Milliman 2000) and also most of the prior studies were confined to a couple of atmospherics such as music, temperature, merchandise scents parking facility, security and privacy, traffic flow inside and out of mall, crowding, coloring and contrast etc. The application of Berman \& Evans atmospheric classification is lack in past studies as well. Thus, this study extends previous researches and focuses on atmospheric variables demonstrated by Berman \& Evans in 1995 and which extends by Turley and Milliman in year 2000. In this study, researchers explore the effect of diverse atmospheric dimensions: External atmospheric variables, general interior atmospheric variables, layout \& design variables and human variables (employee characteristics and uniforms) on consumer behavioral intention towards restaurant by utilizing floor consumers in two districts: Galle and Matara as a sample to address the aforementioned research voids in atmospherics and behavioral intention of literature streams.

\subsection{Research Objectives}

\subsubsection{The Main Objective}

This study was aimed to examine the impact of restaurant atmospherics towards restaurant patrons' behavioral intention in the restaurant business arena.

\subsubsection{The Specific Objectives:}

- To explore the impact of exterior atmospheric variable towards restaurant patrons' behavioral intention in the restaurant business arena.

- To explore the impact of general interior and decoration atmospheric variable towards restaurant patrons' behavioral intention in the restaurant business arena.

- To explore the impact of human atmospheric variable towards restaurant patrons' behavioral intention in the restaurant business arena.

- To explore the impact of layout and design variable towards restaurant patrons' behavioral intention in the restaurant business arena.

- To identify the most significant atmospheric variables which determine restaurant patrons' behavioral intention in the restaurant business arena.

\subsection{Hypothesis}

Hypothesis 1: Exterior atmospheric variable has a positive influence on behavioral intention.

Hypothesis 2: General Interior and Decoration atmospheric has a positive influence on behavioral intention.

Hypothesis 3: Human atmospheric variable has a positive influence on behavioral intention.

Hypothesis 4: Layout and design atmospheric variable has a positive influence on behavioral intention.

Hypothesis 5: Restaurant atmospherics have a positive influence on behavioral intention.

\section{Review of Literature}

\subsection{Atmospherics}

In 1973, Kotler introduced a new concept to consumer behavior stream by defining the term of atmospherics. According to the article, Kotler (1973) defined atmospherics term as the effort to design buying environment to produce specific emotional effects in the buyer that enhance his purchase probability. It presents the "quality of surrounding place" and it consists of tangible and intangible environmental features like scent, lighting, music, furnishings and it's presented as quality of the surrounding space.

The study of Binter (1992) demonstrated that store atmospheric is the deliberate creation of an environment which support to attract customers to the location and hopes to positively affect purchase behaviors. It is vital to understand that customers respond to atmospherics holistically. Turley and Bolton (1999) defined atmospherics as 
a marketing environment which should be carefully sculpted to both induce particular behaviors and evaluations from customers and to appeal to a specific target market. According to Rayburn \&Voss (2013) atmosphere of a service setting had demonstrated as the environment comprises floor layout, music, olfactory and customer interaction with product offerings to accentuate the shopping experience.

Prior studies revealed types of atmospheric variables. Baker (1986) introduced three dimensions of atmospherics: social cues, design cues and ambient cues. Social cues defined as employees and customers within the store. Design cues imply visual elements of a space including color, layout, architecture etc. Ambient dimension refers to nonvisual elements of a space comprising music, lighting, and temperature so forth.

Berman \& Evans (1995) recognized four types of atmospheric variables: Store exteriors, store interiors, layout \& design and point of purchase \& decoration. Store exteriors consist of store front, entrances, window displays, physical characteristics of the building, surrounding area, and parking. The flooring, coloring, lighting, sounds, fixtures, merchandise and cleanliness including to store interiors. The floors space allocation exhibited as layout $\&$ design. The point of purchase $\&$ decoration includes wall decorations, point of purchase displays, signs, pictures and arts, price and product displays. Turley \& Milliman (2000) introduced fifth atmospheric attribute as human variable which include Employee characteristics, uniforms, crowding, privacy and customer characteristics.

Heung and $\mathrm{Gu}$ (2012) stated five atmospherics aspects in their study: facility aesthetics, ambience, spatial layout, employee factors and window in a restaurant setting. The facility aesthetics dimension refers to interior design and décor. The background music, aromas, lighting and temperature comprise in ambience aspect. The Spatial layout consists of furnishing and fixtures. Employee factor implies the appearance and number of Employees. The fifth factor is window of service setting explained as architectural design of building.

Khare (2012) investigated seven attributes with respect mall involvement behavior as ambience, design, interiors, service, assortment, socializing and entertainment. In this study ambience is defined by including music, color, facilities and layout. Design implies color schemes, spaciousness, product and service availability etc. Through service factor tested the influence of staff behavior. The socializing variable focused watching other shoppers, ability to meet friends and people in malls, window shopping etc. In addition to that this work study the effect of entertainment factor comprised the availability of cinema, theatres, food courts etc.

\subsection{Behavioral Intention}

The study of Liu \& Jang (2009) identified patronage intention as a post behavioral intention including Word of Mouth (WOM). Those researchers stated that Customers' post behavioral intention is significantly affected by the aesthetically pleasing and comfortable atmospherics and imply feeling of excitement which in turn led to behavioral intention and WOM. Heung and Gu (2012) stated patronage concept as a component of behavioral intention and which refers to consumers' return intention to a same restaurant setting and revealed that aesthetic and pleasing environment are strongly affecting customer patronizing.

Behavioral intention was demonstrated as the likelihood of both intending to shop at store, buy in store more and recommending it to others (Baker et al. 2002). The study undertaken by Grewal (2003) also provided an identical demonstration for Behavioral intention like Baker et al in 2002. Raajpoot et al. (2008) patronage behavior of restaurant consumers defined as probability of visiting to same restaurant or preference to visit same restaurant at next time and so forth.

\subsection{Atmospherics and Behavioral Intention}

The external variables such as location, accessibility indicated as crucial atmospherics to grab customers to shopping mall since it is more convenience for customers and revealed that location and easy accessibility to store as an important attribute for customers regarding behavioral intention (Raajpoot et al. 2008).

Yavas \& Babakus (2009) found that the accessibility is the prominent factor impact on patronage behavior. The accessibility dimension focus on atmospheric attributes parking facility, security and privacy, traffic flow inside and out of mall, crowding, coloring.

Mathews et al. (2009) revealed that there was a significant relationship between ambiance dimensions: Lighting scents, sounds and so forth with revisit intentions. Heung and $\mathrm{Gu}$ (2012) examined the impact of store atmospherics on consumers' patronage behavior and study explored that atmospherics are directly affecting on customers' return intention in restaurant setting. The patronage intention of customers is affected by the restaurant atmospherics such as facility aesthetic heavily. Customers pay greatest attention on interior design and décor while choosing 
restaurant for dinning visits repetitively.

Khare (2012) stressed that atmospherics of shopping malls induce customers to spend time in restaurants. The atmospheric cues are supporting to develop positive impression about restaurants and affect significantly on consumers' buying and patronage/ loyalty behavior. Ariffin, Bibon \& Abdullah (2012) suggested that creation of a better interior atmosphere is must to grab young consumers to restaurants and especially restaurant managers must develop restaurant atmospherics: interior design and lighting which significant for young restaurant consumers' behavioral intention.

Alhemoud (2008) stated merchandise dimension is a key attribute which impact on restaurants behavioral intension. This work highlighted that quality of merchandise, fairness merchandise prices, variety of merchandise, brand variety are prominent attributes which influence on restaurants selection and behavior. Wanninayake \& Randiwela, 2007). Liu \& Jang (2009) stressed that interior designs \& décor are both vital on behavioral intention of customers. The service providers must persuade to enhance the quality of service by considering target customers' taste, preferences and visual elements: pictures, colors etc. Lighting and cleanliness are strongly affecting on restaurants choice and behavioral decision. Restaurants retailers must set up appropriate lighting system in store since shoppers are willing to choose more lighted restaurants as their shopping destination.

The better in store environment supports to build store traffic and persuade shoppers to spend time in restaurants more. The interior atmospheric factor: music is influencing shopping time of consumers (Yalch \& Spangenberg 2000).

Fowler et al. (2007) remarked that design and layout as an important atmospheric impact on patronage and retailers strive to manage the retail space and manage product category to satisfy target customers' needs in apparel shops. Alhemoud (2008) stated that consumers are highly sensitive to personnel variable in relation to behavioral intention Personal atmospheric consists of staff friendliness etc. Liu \& Jang (2009) remarked that the role plays by the atmospherics are significant to create patronized customers. The attentive service of employees and comfortable atmosphere are also key success factors of restaurant setting. Moreover, professional and friendly employee behavior, employee appearance is more significant on decision regarding the behavioral intention in a service setting.

\section{Methodology}

The present research constituted a descriptive study with cross sectional design and it required gathering both qualitative and quantitative data to attain present research objectives and to test established hypotheses. Primary data were collected by employing Restaurant Intercept Survey method over the randomly selected leading luxury, convenient and intensive service providing restaurant outlets with stunning atmosphere which operate in two districts, namely Galle and Matara in Southern Province, Sri Lanka. Stratified random sampling technique was applied to select 300 respondents and administered self - developed structured questionnaire randomly among twenty-five restaurants located Galle and Matara districts for collecting primary data. Twenty-five middle and upscale full-service restaurants which are chosen according to the "Yelp", an application used for finding nearby popular restaurants.

The questionnaire consisted of three phrases, phrase one focused demographic profile of patrons, phrase two focused on four restaurant atmospheric variables and behavioral intention was focused over phrase three. The behavioral intention was tested over three dimensions such as likelihood, willing to purchase more in future and Word of Mouth (WOM). Phrase two was applied five-point Likert scale ranging from strongly disagree (1) to strongly agree (5) for present study. Besides, a couple of unstructured interviews were also conducted with intercept patrons randomly and restaurants managers to gain restaurants patrons view regarding restaurants atmosphere. The secondary data regarding the restaurant industry, restaurants were gathered through Central Bank reports, Census department reports, web sites, newspaper articles and other publications so forth.

\subsection{Conceptual Framework}

Independent variables and dependent variable of conceptual model as shown in figure 1 . The measures were based upon the foregoing review of literature. 


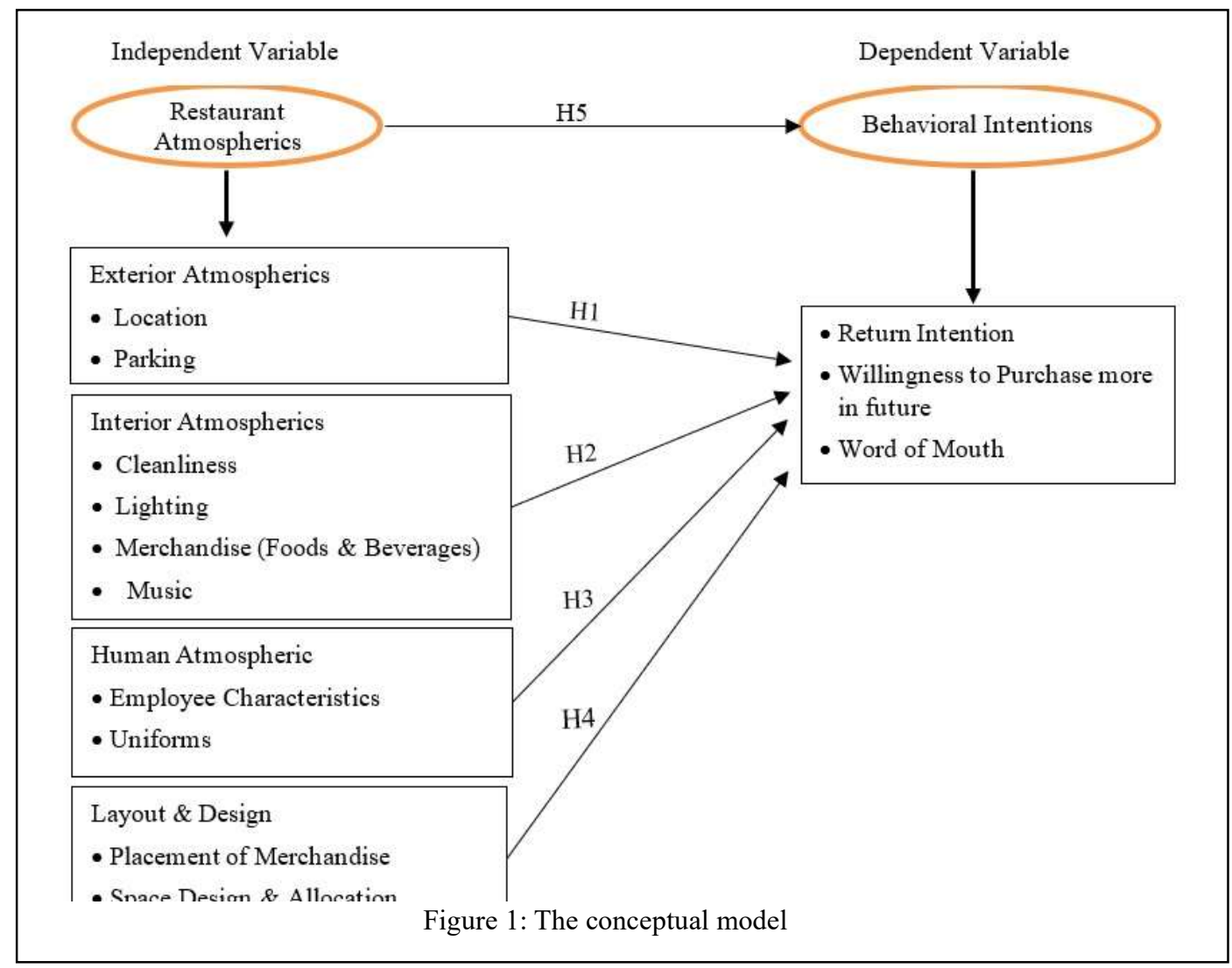

\section{Results}

With regard to the quantitative analysis, Statistical package for social science (SPSS) 20 were employed for the data entry and to analyze the results. The reliability was tested for both independent and dependent variables by computing Cronbach's Alpha value. Thus, questionnaire consisted of the measures which have Cronbach's alpha coefficient was greater than 0.7 by considering cut - off point as 0.7 (Nunnally cited in Heung and Gu 2012: Bagozzi and Yi as cited in Raajpoot et al. 2008). Kaiser- Meyer- Olkin (KMO) and Bartlett's Test of Sphericity were utilized to test the content validity of items of the questionnaire. Descriptive statistics such as mean, frequency and standard Deviation (Std. deviation) were computed for demographic profile of respondents. Next ANOVA test employed to show the fitness of the overall model at the beginning of this analysis and regression analysis were applied to identify the impact of restaurants atmospherics on behavioral intention. The coefficient of Beta was computed to determine the salient atmospheric with degree of influence.

Table 1: Confirmatory Factor Analysis

\begin{tabular}{|l|c|c|}
\hline \multicolumn{1}{|c|}{ Variable } & $\begin{array}{c}\text { Cronbach's } \\
\text { Alpha }\end{array}$ & KMO \\
\hline Exterior Atmospherics & 0.926 & 0.715 \\
\hline General Interior Atmospherics & 0.956 & 0.640 \\
\hline Layout \& Designs Atmospherics & 0.906 & 0.624 \\
\hline Human Atmospherics & 0.926 & 0.674 \\
\hline Behavioral Intention. & 0.778 & 0.602 \\
\hline
\end{tabular}

Scale's Cronbach's Alpha 0.976

Extraction Method: Principal Component Analysis; Rotation Method: Promax with Kaiser Normalization 


\subsection{ANOVA Testing Analysis}

In the present study the impact of four atmospheric variables on behavioral intention were tested over the significance level of $\mathrm{p}<0.005$ as the Standardized regression coefficient. The summary of this study is shown in Table 2.

Table 2: Results of Hypothesis Testing

\begin{tabular}{|l|l|c|c|}
\hline \multicolumn{2}{|c|}{ Hypotheses } & Sig: & Results \\
\hline H1: & Exterior Atmospherics have an impact on behavioral intention & 0.027 & Supported \\
\hline H2: & Interior Atmospherics have an impact on behavioral intention & 0.000 & Supported \\
\hline H3: & Human Atmospherics have an impact on behavioral intention & 0.000 & Supported \\
\hline H4: & Layout \& design Atmospherics have an impact on behavioral intention & 0.050 & Supported \\
\hline H5: & Restaurants Atmospherics have an impact on behavioral intention & 0.037 & Supported \\
\hline
\end{tabular}

According to the table 2, it is evidenced that there is a relationship between exterior atmospherics and restaurants behavioral intention, since the significant value which is $p<0.05$. Thus, the overall model is significant, suggesting that exterior atmospheric variable is a significant predictor of consumers restaurant behavioral intention. As well as the result of the ANOVA test depicted in table 2 , that $\mathrm{p}=0.000$ which is illustrated that overall model is significant and suggesting that general interior atmospheric variable is a significant predictor of patron's restaurant behavioral intention.

The ANOVA test of Layout \& Design and behavioral intention indicated the Significant value as 0.050 which is $\mathrm{p}<0.05$. Thus, overall model is significant, which is meaning that layout \& design is a significant predictor of restaurant behavioral intention.

According to the ANOVA test the human (employee) atmospheric variable is a significant predictor of restaurants behavioral intention by indicating significant value as 0.000 which is $p<0.05$. The overall significant value as 0.037 which is less than 0.05 , thus it evidenced that restaurants atmospheric variable is a significant predictor of behavioral intention of restaurants' patrons in Sri Lanka.

\subsection{Regression Model}

$$
\mathbf{P}_{\mathbf{i}}=\mathbf{a}+\mathbf{b}_{1}\left(\mathbf{V}_{1}\right)+\mathbf{b}_{2}\left(\mathbf{V}_{2}\right)+\mathbf{b}_{3}\left(\mathbf{V}_{3}\right)+\mathbf{b}_{4}\left(\mathbf{V}_{4}\right)
$$

According to the model pi stands for behavioral intention and $v 1, v 2, v 3$ and $v 4$ stand for exterior, general interior, human atmospheric and layout and design variables respectively.

The atmospheric variables with various degrees of significance resulting from the regression analysis are then shown in order of importance based on their standardized regression coefficient which is Beta value. Thus, an atmospheric variable with a high positive Beta coefficient is more likely to suggest that it has strong influence to determine the behavioral intention (Juwaheer et al. 2013).

The four independent variables with various degrees of significance resulting from regression analysis were shown in Table 3. The degree of impact of the variable on behavioral intention was determined over the standardized Regression coefficient (Beta coefficient).

Table 3: Summary of Regression Analysis

\begin{tabular}{|l|c|c|c|c|c|}
\hline \multicolumn{1}{|c|}{ Variable } & B & Beta & R square & t & F \\
\hline Constant & 3.911 & & 0.022 & 26.55 & 4.391 \\
\hline V1: Exterior & 0.044 & 0.1 & 0.01 & 1.42 & 2.017 \\
\hline V2: Interior & 0.194 & 0.292 & 0.085 & 4.29 & 18.405 \\
\hline V3: Human (Employees) & 0.188 & 0.267 & 0.071 & 3.898 & 15.192 \\
\hline V4: Layout \& Design & 0.061 & 0.139 & 0.019 & 1.97 & 3.88 \\
\hline
\end{tabular}

It can be seen that general interior atmospheric variable (Beta $=0.292, \mathrm{t}=4.29, \mathrm{~F}=18.405)$ and human atmospheric variable $(\mathrm{Beta}=0.267, \mathrm{t}=3.898, \mathrm{~F}=15.192)$ had the greatest effect on behavioral intention. In addition, layout $\&$ 
design atmospheric variable $($ Beta $=0.139, \mathrm{t}$ value $=1.97, \mathrm{~F}=3.88)$ was the next most significant variable which impact on behavioral intention among the four atmospherics. The atmospherics relating to exterior atmospheric variables $(\mathrm{Beta}=0.1, \mathrm{t}$ value $=1.42, \mathrm{~F}=2.017$ ) have also been significant to determine the behavioral intention.

Thus, the standardized regression equation thus can be expressed as follows

$$
\mathrm{Pi}=3.911+0.044\left(\mathrm{~V}_{1}\right)+0.194\left(\mathrm{~V}_{2}\right)+0.188\left(\mathrm{~V}_{3}\right)+0.061\left(\mathrm{~V}_{4}\right)
$$

Thus, this study unveiled that exterior atmospherics linked with behavioral intention and it can be seen that restaurants exterior atmospherics have a positive impact on behavioral intention and disclosed that customers are willing to patronize the store which has better exterior atmospheric. Next hypothesis examined the impact of general interior atmospherics on behavioral intention by utilizing cleanliness and lighting merchandise as dimensions of interior atmospheric. The results suggested that general interior atmospheric variable has a positive impact on restaurants behavioral intention. The hypothesis three posited that human (employees) atmospheric variable has a positive influence on consumers 'behavioral intention. Present research findings have shown that layout \& design of restaurants has positive influenced on restaurants patronizing. The final hypothesis (H5) indicated that restaurants atmospherics influence on behavioral intention. Thus, such result assertion the findings stated in the earlier studies. Binter (1992) expressed that behavioral intention is influenced by physical store atmosphere. As well as present findings noted that consumers' behavioral intention is affected by restaurants atmospherics.

\section{Conclusion}

This study revealed that all four variables of restaurants atmospherics had a significant impact on customers' behavioral intention, general interior atmospheric variable and human atmospheric variable had the greatest effect on behavioral intention. In other words, consumers perceptions of restaurants floor workers, meals, beverages, cleanliness with well illumination appear to be the major determinants of behavioral intention.

In addition, the next significant variable was layout \& design and it indicated that specially take- away consumers are willing to revisit restaurants which are supporting to get in and out within short time. Thus, it is essential to train and develop mangers to enhance knowledge regarding the foods and beverages placements including logical arrangement of foods, ease of findings foods \& beverages, generate more convenient layout over ease of moving and walking on restaurant floor, easy access cashier counter and sanitary facilities etc. The atmospherics relating to exterior atmospheric variables have also been less significant to determine the behavioral intention.

The present study had outlined to examine whether behavioral intention is influenced by restaurants atmospherics by limiting the four atmospheric variables: Exterior, General Interior, Human, and Layout \& Design which were introduced by Berman and Evans in 1995 and extended by Turley and Milliman in year 2000. Thus, this study was utilized couple of dimensions (atmospherics) presented in such classifications and rest of variables and dimensions are able to examine further. Recently government restaurants like Hela-Bojuna outlets are opening throughout the country and outlet surroundings has crafted by focusing Sri Lankan tradition. Thus, future researchers are able to select such traditional restaurants as research setting and examine the impact of restaurants atmospherics on behavioral intention. Moreover, this study was based on the limited medium scale restaurants chains operated in Galle and Matara districts and ignore the small- and large-scale restaurants. Thus, researcher suggests to undertake future researches in those settings too.

\section{References}

Alhemoud, A. M. (2008), 'Shopping Behavior of Supermarket Consumers in Kuwait', Journal of Business \& economics Research, Vol.6, no.3, pp.47-58.

Anic, I .D. , Rajh, E., \& Bevanda (2012), 'Decision-Making Styles of Young Consumers in Bosnia and Herzegovina'. Journal of Services Marketing, Vol.24, no.4, pp.283-293.

Ariffin, H .F. , Bibon, M .F. \& Abdullah, R .P. S. R. (2012), 'Restaurant's Atmospheric Elements: What the customer wants'. Journal of Social and Behavioral sciences, Vol.38, pp.380-387.

Baker, J., \& Grewal, D. (1994), 'The Influence of Store Environment on Quality Inferences and Store Image'. Journal of the Academy of Marketing Science, Vol. 22, pp. 328-339.

Baker, J ., Parasuraman, A .P, Grewal, D . \& Voss, G. B. (2002), 'The Influence of Multiple Store Environment Cues on Perceived Merchandise Value and Patronage Intentions', Journal of Marketing, Vol. 66, pp. 120-141.

Berman, B., Evans, \& J.R. (1995), Retail Management: A Strategic Approach (6th ed.), Prentice Hall: Inc., Englewood.

Binter, M . J. (1992), ' Service Scapes: The Impact of Physical Surroundings on Customers and Employees', Journal of 
Marketing, Vol. 56 (2), pp. 57-71.

Blum, S. C. (1996), 'Organizational Trend Analysis of The Hospitality Industry: Preparing for Change', International Journal of Contemporary Hospitality Management, Vol.8(7), pp.20-32.

Burnkrant, R. E . \& Page, J .T. (1982), ‘An Examination of the Convergent, Discriminant and Predictive Validity of Fishbein's Behavioral Intention Model', Journal of Marketing Research, Vol. 119 (4), pp. 550-561.

Fowler, D .C., Wesley, S. C., \& Vazquez, M. E. (2007), 'Simpatico in Store Retailing : How Immigrant Hispanic Emic Interpret U.S. Store Atmospherics and Interactions With Sales Associates', Journal of Business Research, Vol.60, pp. 50-59.

Grewal, D., Baker, J., Levy, M., \& Voss, G. B. (2003), 'The Effects of Wait Expectations and Store Atmosphere Evaluations on Patronage Intentions in Service - Intensive Retail Stores', Journal of Retailing, Vol. 79, pp. 259-268.

Haryana, R. (2012), 'Influence of Mall Attributes and Demographics on Indian Consumers' Mall Involvement Behavior: An Exploratory Study', Journal of Targeting, Measurement and Analysis for Marketing, Vol. 20, (3 / 4), pp. 192-202.

Heung, V. C. S., \& Gu, T. (2012), 'Influence of Restaurant Atmospherics on Patron Satisfaction and Behavioral Intention', International Journal of Hospitality Management, Vol. 31, pp.1167-1177.

Hoffman, K. D. , \& Turley, L. W. (2002), 'Atmospherics, Service Encounters and Consumer Decision Making: An Integrative Perspective', Journal of Marketing Theory and Practice, Vol.10 (3 summer),pp. 33-47.

Juwaheer, T .D., Pudaruth, S., \& Ramdin, P. (2013), 'Enhancing Customer Shopping Experience in Malls of Emerging Countries- The Mauritius Experience', World Journal of Entrepreneurship, Vol.9 (2/3), pp.178-190.

Khare, A. (2012), 'Influence of Mall Attributes and Demographics on Indian consumers' Mall Involvement Behavior: An Expletory study', Journal of Targeting, Measurement and Analysis for Marketing, Vol. 20 (3/4), pp.192-202.

Kumar, A., \& Kim, Y. K (2014), 'The store - as - a Brand Strategy: The Effect of Store Environment on customer Responses', Journal of Retailing and Consumer Services, Vol.21.

Liu, Y., \& Jang, S. (2009), 'The Effects of Dining Atmospherics: An Extended Mehrabian Russell model', International Journal of Hospitality Management, Vol.28, pp. 494-503.

Mehta, R., Sharma, N.K. \& Swami, ( 2014), 'A Typology of Indian Hypermarket Shoppers Based on Shopping Motivation'. International Journal of Retail \& Distribution Management, Vol. 42 , no. 1, pp. 40-55.

Michon, R., Chebat , J.C., \& Turley, L.W. (2005), 'Mall Atmospherics: The Interaction Effects of The Mall Environment on Shopping Behavior', Journal of Business Research, Vol. 58, pp. 576-583.

Min, H. (2010), 'Evaluating The Comparative Service Quality of Supermarkets Using the Analytic Hierarchy Process', Journal of Services Marketing, Vol. 24 , no 4, pp. 283-293.

Mortimer, G. ,\& Clarke, P. (2011), 'Supermarket Consumers and Gender Differences Relating to Their Perceived Importance Levels of Store Characteristics', Journal of Retailing and Consumer Services, Vol. 18, pp. 575-585.

Mower, J .M., Kim, M. \& Childs, M. L. (2012), 'Exterior Atmospherics and Consumer Behavior: Influence of Landscaping and window Display', Journal of Fashion Marketing Management, Vol.16, no. 4, pp.442-453.

Prasad, C. J.,\& Aryasri,A. R. (2011), 'Effect of Shopper Attributes on Retail Format Choice Behavior for Food and Grocery Retailing in India', International Journal of Retail\& Distribution Management, Vol. 39, no.1, pp. 68-86.

Prasad, C. J. S., \& Reddy, D. R. (2007), 'A Study on Role of Demographic and Psychographic Dynamics in Food and Grocery Retailing in India', Journal of Business Perspective, Vol.1, no.4.

Raajpoot, N.A., Sharma, A., \& Chebat, J.C. (2008), 'The Role of Gender and Work Status in Shopping Center Patronage', Journal of Business Research, Vol.61, pp.825-833.

Rayburn, S.W., Voss, K.E. (2013), ‘A Model of Consumer's Retail Atmosphere Perceptions': Journal of Retailing and Consumer services, Vol. 20, pp. 400-407.

Sands, S., Oppewal, H., \& Berverland, M. (2009), 'The Effects of In- Store Themed Events on Consumer Store Choice Decisions', Journal of Retailing and Consumer Services, Vol.16, pp.386-395.

Sanlier, N., \& Karakus, S. S. (2010), 'Evaluation of Food Purchasing Behavior of Consumers from Supermarkets', British food journal, Vol.112, no. 2, pp. 140-150.

Turley, L. W., \& Milliman, R. E. (2000), 'Atmospheric Effects on Shopping Behavior: A Review of the Experimental Evidence', Journal of Business Research, Vol.49, pp.193-211.

Walsh, G., Hennig, T.T., Mitchell, V.W.,\& Wiedmann, K.P. (2001), 'Consumers' Decision-Making Style as a Basis for Market Segmentation', Journal of Targeting, Measurement \& Analysis for Marketing, Vol.10, no.2, pp.117-132.

Wanninayake, W. M. C. B., \& Randiwela, P. (2007), 'The Impact of Visual Merchandising on Consumer Store Choice Decisions in Sri Lankan Supermarkets',7th Global conference on Business \& Economics, Rome 13-14 October 2007.

Yavas,U., \& Babakus, E. (2009), 'Modeling Patronage Behavior: a Tri-Partite on Conceptualization', Journal of Consumer Marketing, Vol.26, no. 7,pp. 516-526. 